\title{
INDEX
}

Atiyah, M. F., Patodi, V. K. and Singer, I. M. Spectral asymmetry and Riemannian geometry.

Babbage, D.W. Note on the generalised Wallace theorem and related topics

Baker, A. and Coates, J. Fractional parts of powers of rationals . . . . .

Bedding, R. J. and Willis, J. R. Arrivals associated with a class of self-similar problems

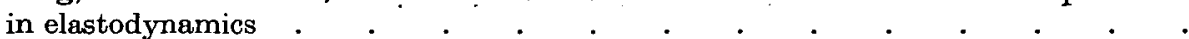

Brown, G. and Moran, W. Coin tossing and powers of singular measures . . . . $\quad 349$

Budden, K. G. The critical coupling of modes in a tapered earth-ionosphere wave guide $\quad 567$

Chad wick, P. and Currie, P. K. On the existence of transverse elastic acceleration waves $\quad 405$

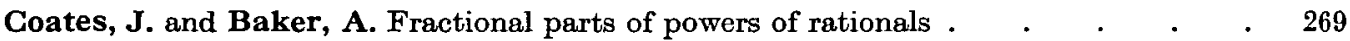

Cohn, P. M. Presentations of skew fields. I. Existentially closed skew fields and the Nullstellensatz

Greegan, Aileen, Dyke, P. P. G. and Johnson, J. A. A singularity in an oceanic boundary layer .

Currie, P.K. and Chadwick, P. On the existence of transverse elastic acceleration waves

Dikshit, H. P. and Kumar, A. Absolute total-effectiveness of $\left(N, p_{n}\right)$ means I

Dark, R. S. A complete group of odd order .

Dyke, P. P. G., Johnson, J. A. and Creegan, Aileen. A singularity in an oceanic boundary layer

Eagles, P. M. and Fraenkel, L. E. On a theory of laminar flow in channels of a certain class. II .

Edge, W. L. A footnote on the mystic hexagram

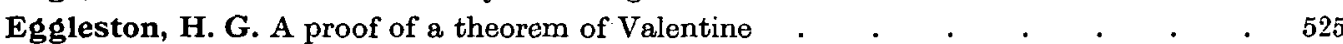

Ezeilo, J. O. C. A further result on the existence of periodic solutions of the equation $\ddot{x}+a \ddot{x}+b \dot{x}+h(x)=p(t, x, \dot{x}, \ddot{x})$.

Fiorini, S. Some remarks on a paper by Vizing on critical graphs $\quad . \quad$. $\quad . \quad$. 475

Fraenkel, L. E. and Eagles, P.M. On a theory of laminar flow in channels of a certain class. II .

Fremlin, D. H. Inextensible Riesz spaces

Friedman, H. Adding propositional connectives to countable infinitary logic . . .

Garling, D. J. H. Lattice bounding. Radonifying and summing mappings . . . 327

Godwin, A. N. Topological bifurcation for the double cusp polynomial $\quad$. $\quad$. $\quad$. $\quad 293$

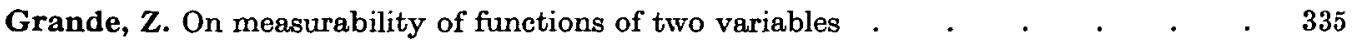

Gregory, R. D. The non-existence of standing modes in certain problems of linear elasticity .

Griffiths, J. B. On the superposition of gravitational waves . $\quad . \quad$. $\quad . \quad$. $\quad . \quad 559$

Grimmett, G. R. and McDiarmid, C. J. H. On colouring random graphs . . . $\quad$ - $\quad 313$

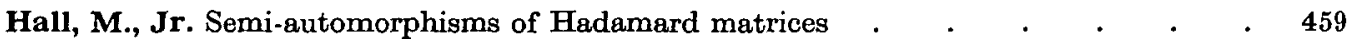

Hartley, B. Groups of automorphisms of Abelian $\mathfrak{G}_{1}$ - groups $\quad$. $\quad$. $\quad$ • $\quad$. $\quad . \quad 241$

Hayman, W. K. and Weitsman, A. On the coefficients and means of functions omit-

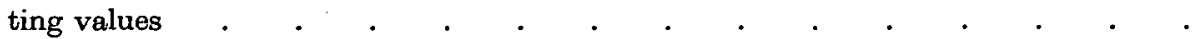

Heading, J. Further transformable $n$th order differential equations with transition

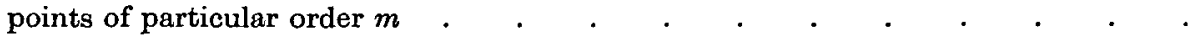

Hinton, D. B. and Lewis, R. T. Discrete spectra criteria for singular differential opera-

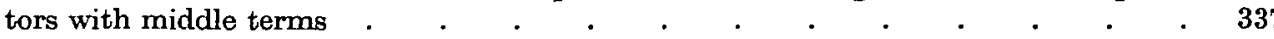

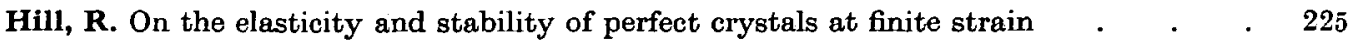


Johnson, J. A., Creegan, Aileen and Dyke, P. P. G. A singularity in an oceanic boundary layer.

Kingman, J. F. C. Geometrical aspects of the theory of non-homogeneous Markov chains

Kumar, A. and Dikshit, H. P. Absolute total-effectiveness of $\left(N, p_{n}\right)$ means I . .

Kuttner, B. Cesàro iterations of Hausdorff matrices c c c c c c . .

Larman, D. G. and Mani, P. Almost ellipsoidal sections and projections of convex bodies

Lewis, R. T. and Hinton, D. B. Discrete spectra criteria for singular differential operators with middle terms

Lillington, J. N. Some extremal properties of convex sets . . . . . . . . .

McDiarmid, C. J. H. and Grimmett, G. R. On colouring random graphs . . . $\quad 313$

McGinley, W. G. and Sibson, R. Dissociated random variables . $\quad$. $\quad$ - $\quad$. $\quad$. $\quad 185$

McKee, W. D. A 'two turning-point' problem in fluid mechanics . . . . . . . $\quad 581$

Mani, P. and Larman, D. G. Almost ellipsoidal sections and projections of convex bodies $\quad 529$

Masser, D. W. Linear forms in algebraic points of Abelian functions. I. $\quad$. $\quad$. $\quad$ - $\quad 499$

Mayer, S. J. On the characters of the Weyl group of type D $\quad . \quad$. $\quad . \quad$. $\quad \begin{array}{lllll} & & 259\end{array}$

Moran, W. and Brown, G. Coin tossing and powers of singular measures . . . $\quad$. $\quad 365$

Naylor, D. On an integral transform associated with a condition of radiation, part $2 \quad . \quad 189$

Neudecker, W. On twin 'primes' and gaps between successive 'primes' for the Hawkins Randon Sieve .

Ogden, R. W. A note on variational theorems in finite elastostatics . . . . .

Patodi, V. K., Singer, I. M. and Atiyah, M. F. Spectral asymmetry and Riemannian geometry. I

Peregrine, D. H. and Smith, R. Stationary gravity waves on non-uniform free streams: jet-like streams

Pólya, G. Partitions of a finite set into structured subsets

Rado, R. One-transversal families .

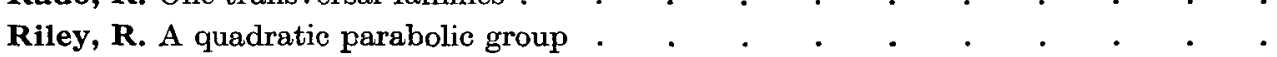

Sanderson, B. J. The simplicial extension theorem . . . . . . . . .
Seymour, P. D. and Welsh, D. J. A. Combinatorial applications of an inequality from statistical mechanics

Shanbhag, D. N. Some results on the decomposability of the distributions of quadratic expressions

Sibson, R. and McGinley, W. G. Dissociated random variables ..$\quad \cdot \cdot \cdot \cdot \cdot$
Singer, I. M., Atiyah, M. F. and Patodi, V. K. Spectral asymmetry and Riemannian geometry. I

Smith, R. and Peregrine, D. H. Stationary gravity waves on non-uniform free streams: jet-like streams

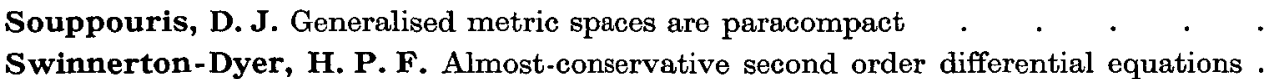

Theobald, C. M. An inequality for the trace of the product of two symmetric matrices

Thompson, M. Spectral manifolds for the perturbed Schrödinger operator in $L^{p}\left(R^{n}\right)$.

Tomkinson, M. J. A Frattini-like subgroup .

Weitsman, A. and Hayman, W. K. On the coefficients and means of functions omitting values

Welsh, D. J. A. and Seymour, P. D. Combinatorial applications of an inequality from statistical mechanies

Willis, J. R.'and Bedding, R. J. Arrivals associated with a class of self-similar problems in elastodynamics

Yeadon, F. J. Non-commutative $L^{p}$-spaces
Zemanian, A. H. The Kontorovich-Lebedev transformation on distributions of compact support and its inversion. 


\section{BACK NUMBERS}

The present prices of back numbers of the Proceedings are:

\begin{tabular}{ccc} 
Volumes & \multicolumn{1}{c}{ Years } & $£$ per volume \\
$1-30$ & $1844-1934$ & 5.00 \\
$31-50$ & $1935-1954$ & 7.50 \\
$51-60$ & $1955-1964$ & 10.00 \\
$61-64$ & $1965-1968$ & 12.50 \\
$65-70$ & $1969-1971$ & 10.00 \\
$71-$ & $1972-$ & 12.50
\end{tabular}

Orders for back numbers placed during 1975 will be eligible for discount on the following scale

$\begin{array}{cc}\text { Total order } & \begin{array}{c}\text { Rate of } \\ \text { discount }\end{array} \\ £ 26-£ 50 & 5 \% \\ £ 51-£ 100 & 10 \% \\ £ 101-£ 200 & 15 \% \\ \text { above } £ 200 & 25 \% \\ \text { Orders and enquiries should be addressed to } \\ \text { Mathematical Proceedings } \\ \text { Cambridge Philosophical Society } \\ \text { Bene't Street } \\ \text { Cambridge } \\ \text { England }\end{array}$




\section{Mathematical Proceedings of \\ the Cambridge Philosophical Society \\ MPCPCO 77 (Pt 3) 447-6r5 (I975) 0305-004I May 1975}

\section{CONTENTS}

RADO, R. One-transversal families + . . . . . . . . . . 447

PóIYA, G. Partitions of a finite set into structured subsets . . . . . . . . 453

Harr, M. JR. Semi-automorphisms of Hadamard matrices . ‥. . . . 459

FroRTNI, S. Some remarks on a paper by Vizing on critical graphs . . . . 475

SeYmour, P. D. and WersH, D. J.A. Combinatorial applications of an inequality from

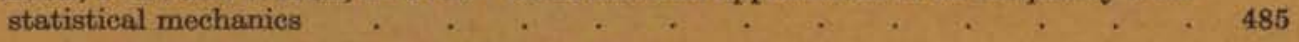

SANDFRson, B.J. The simplicial extension theorem . . . . . . . . 497

Massier, D. W. Linear forms in algebraic points of Abelian functions. I . . . . 499

Lmingmon, J. N. Some extremal properties of eonvex sets _ . . . . . 515

Egrmeston, H. G. A proof of a theorem of Valentine . . . . . . . . 525

Larman, D. G. end MaNr, P. Almost ellipsoidal sections and projections of eonvex bodies . . . . . . . . . . . . . . 529

EzertL, J. O.C. A further result on the existence of periodic solutions of the equation $\ddot{x}+a \ddot{x}+b \dot{x}+h(x)=p(t, x, \dot{x}, \ddot{x})$. . . . . . . .

Shanвнag, D. N. Some results on the decomposability of the distributions of quadratic expressions . $. \quad . \quad . \quad . \quad . \quad . \quad . \quad$.

Griftrins, J. B. On the superposition of gravitational waves . . . . $\quad . \quad$. 559

BUDDEA, K. G. The critieal coupling of modes in a tapered earth-ionosphere wave guide 567

MoKres, W. D. A two turning-point problem in fluid mechanies . . . . . 581

Wrins, J. R. and BeDDIrG, R.J. Arrivals associated with a class of self-similar problems in elastodynamics . . . . . . . . . . . . 591

OGDeN, R. W. A note on variational theorems in non-linear elastostaties ..$\quad .609$

C. The Cambridge Philosophical Society, 1975

CAMBRIDGE UNIVERSITY PRESS

BENTLEY HOUSE, 200 EUSTON ROAD, LONDON NWI $2 D B$

32 EAST 57 TH STREET, NEW YORK, N.Y.IOO22

Price $£ 4.80$ net (U.S.A. and Canada US \$15.50)

1975 subscription price $£ 12$ per volume ( $£ 24$ per annum) net post free

(US $\$ 38.00$ per volume (US $\$ 76.00$ per annum) in U.S.A. and Canada) 